\title{
Eagle syndrome with hidden stylocarotid syndrome examined using dynamic ultrasonography: illustrative case
}

\author{
Yukiko Tanaka, MD, ${ }^{1,2}$ Hidenori Anami, MD, ${ }^{1,2}$ Hiroyuki Kurihara, MD, ${ }^{1,2}$ Satoru Miyao, MD, ${ }^{1,2}$ Hidetoshi Nakamoto, MD, ${ }^{1,2}$ \\ Yuichi Kubota, MD, DMedSci, ${ }^{1,2}$ and Takakazu Kawamata, MD, $\mathrm{PhD}^{2}$ \\ 1Department of Neurosurgery and Stroke Center, TMG Asaka Medical Center, Saitama, Japan; and ${ }^{2}$ Department of Neurosurgery, Tokyo Women's Medical University,
Tokyo, Japan
}

\begin{abstract}
BACKGROUND Eagle syndrome, or elongated styloid process syndrome, is a rare cause of cerebral infarction. When the styloid process is elongated but the internal carotid artery (ICA) is morphologically normal on three-dimensional computed tomography angiography (3D-CTA), determining the causal relationship between elongation and cerebral infarction is difficult.

OBSERVATIONS The patient was a 27-year-old man who experienced two left cerebral infarctions in 3 months. On 3D-CTA, the styloid process was elongated, but the structure of the ICA was normal. When the patient's neck was rotated leftward, the peak systolic velocity and pulsatility index increased (shown via dynamic subtraction ultrasonography) and ICA stenosis was evident (shown via subtraction angiography). The styloid process was removed, and the cerebral infarction did not recur in the 2 years after surgery.
\end{abstract}

LESSONS This is the first report to document that indirect compression of ICA by the styloid process can cause Eagle syndrome. The blood flow changes of the ICA on dynamic ultrasonography revealed morphological changes that were hidden on 3D-CTA or nondynamic subtraction angiography.

https://thejns.org/doi/abs/10.3171/CASE21286

KEYWORDS Eagle syndrome; elongated styloid process; stroke; dynamic ultrasonography; surgery

Eagle syndrome was first reported by W.W. Eagle in 1937, ${ }^{1}$ who attributed its symptoms to elongation of the styloid process or calcification of the stylohyoid ligament. The styloid process arises from the base of the temporal bone and connects to the stylohyoid ligament. It normally ranges in length from 2.5 to $4 \mathrm{~cm}^{2-4}$ and is considered elongated in most reports when more than $3 \mathrm{~cm}$ long. ${ }^{4,5}$ The incidence of styloid process elongation is $4 \%$ to $33.4 \%,{ }^{6-8}$ however, only a few cases become symptomatic.

There are two clinical presentations of Eagle syndrome. One is characterized by throat pain, facial pain, dysphagia, or pharyngeal foreign body sensation. The other, termed "stylocarotid syndrome," is characterized by transient ischemic attack or stroke due to stenosis, occlusion, or dissection. ${ }^{9-11}$

We report a case in which dynamic ultrasonography revealed internal carotid artery (ICA) stenosis associated with elongation of the styloid process.

\section{Illustrative Case}

The patient was a 27 -year-old man with no particular medical history. He experienced a sudden onset of dysarthria and was diagnosed with left cerebral infarction at a different hospital. Cerebral vascular imaging showed no occlusion or stenosis. Transthoracic and transesophageal echocardiography results and the levels of several autoantibodies were normal. The patient's neurological status returned to normal, and he was discharged after receiving single antiplatelet therapy.

He was referred to our hospital 3 months later because of transient right hemiparesis. On physical examination, his consciousness level was Glasgow Coma Scale E4V5M6, and he complained of mild left motor weakness. The manual muscle test score for the left extremities was 4 out of 5 ; he was otherwise neurologically normal.

Head magnetic resonance imaging (MRI) showed small cerebral infarctions in the left parietal lobe (Fig. 1A). No major artery stenosis

ABBREVIATIONS 3D-CTA = three-dimensional computed tomography angiography; DSA = digital subtraction angiography; ICA = internal carotid artery $\mathrm{MRI}=$ magnetic resonance imaging; $\mathrm{PI}=$ pulsatility index; $\mathrm{PSV}=$ peak systolic velocity.

INCLUDE WHEN CITING Published June 28, 2021; DOI: 10.3171/CASE21286.

SUBMITTED May 7, 2021. ACCEPTED May 18, 2021.

(C) 2021 The authors, CC BY-NC-ND 4.0 (http://creativecommons.org/licenses/by-nc-nd/4.0/). 

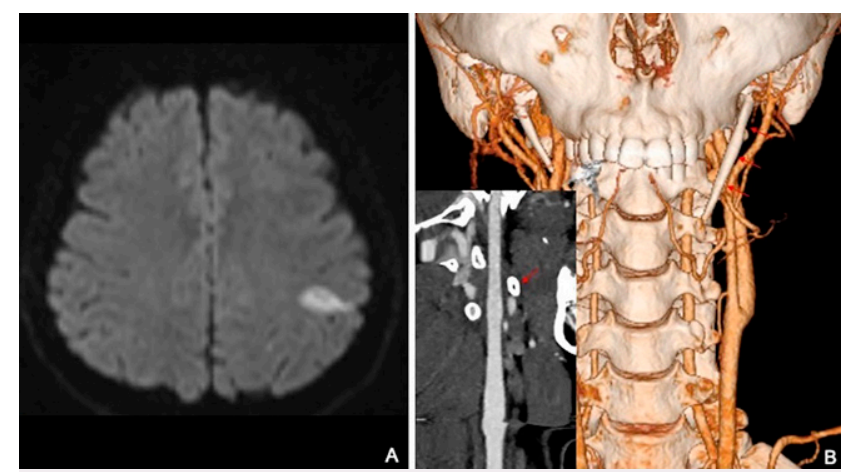

FIG. 1. A: Diffusion-weighted MRI showing a cerebral infarction in the left hemisphere. B: 3D-CTA showing elongation of the left styloid process (red arrows).

was observed on MR angiography. Dual antiplatelet therapy was initiated, and the symptoms gradually resolved. Laboratory data showed no coagulation disorders. No abnormalities were detected on transthoracic or transesophageal echocardiography. Three-dimensional computed tomography angiography (3D-CTA) revealed an elongated left styloid process (Fig. 1B); however, no occlusion of the intracranial or extracranial arteries was observed. The elongated process was approximately $5 \mathrm{~cm}$ long and ran close to the left ICA.

No obvious structural or blood flow abnormalities were noted on ultrasonography. Dynamic ultrasonography with head rotation showed that the peak systolic velocity (PSV) and pulsatility index (PI) increased when the head was rotated to the left but not in other directions (Fig. 2). Digital subtraction angiography (DSA) revealed focal left ICA stenosis at the crossing point of the styloid process upon head rotation to the left (Fig. 3).

We thought that intermittent ICA stenosis caused blood flow turbulence, which resulted in cerebral infarction. We then surgically removed a portion of the left stylomastoid process (up to $\sim 3.5 \mathrm{~cm}$ long) using a transcervical approach (Figs. 4 and 5A). After surgery, the patient did not complain of any neurological symptoms. Postoperative DSA showed no morphological changes upon head movement (Fig. 5B). No recurrence of stroke had occurred 2 years after surgery.

\section{Discussion}

\section{Observations}

When an elongated styloid process accompanies a stroke, direct compression of the ICA by the process usually causes stenosis, occlusion, dissection, or other morphological blood vessel-related abnormality, making it easy to determine the causal relationship between elongated styloid process and a stroke. However, in our case, no obvious morphological abnormalities of the ICA were found other than elongation of the styloid process.

Anatomically, the styloid process is a columnar bone arising from the bottom of the temporal bone. It runs anteromedially and inferiorly between the internal and external carotid arteries, connects to the stylohyoid ligament, and is continuous with the hyoid bone. Cervical rotation can cause the styloid process or the stylohyoid ligament to compress the ICA, even indirectly. In particular, ipsilateral cervical rotation tends to increase ICA compression due

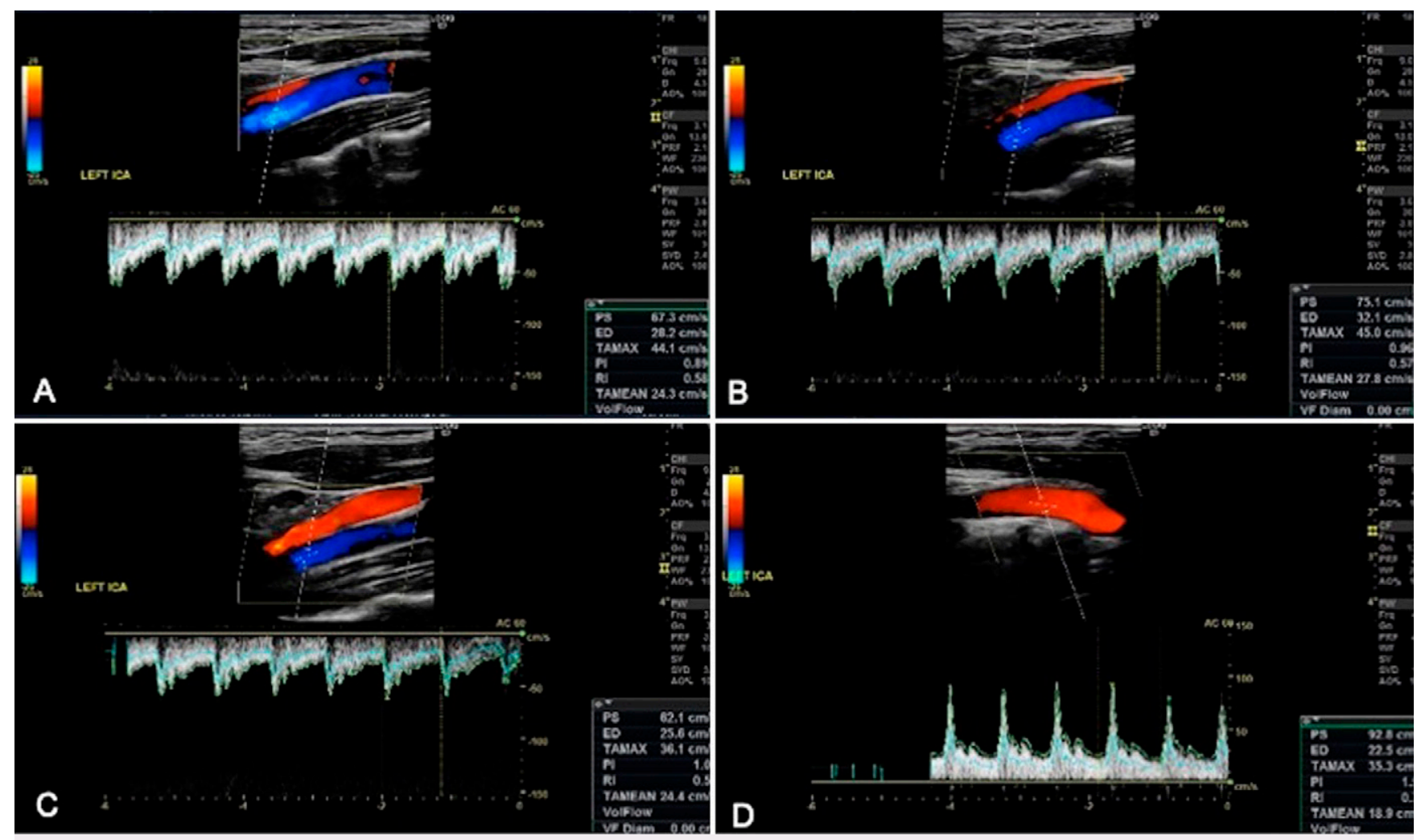

FIG. 2. Cervical ultrasonography showing no obvious blood flow differences in the head in the neutral (A), extension (B), and flexion (C) positions. Flexing the head downward and to the left caused the PSV and PI to increase relative to the other positions (D). 

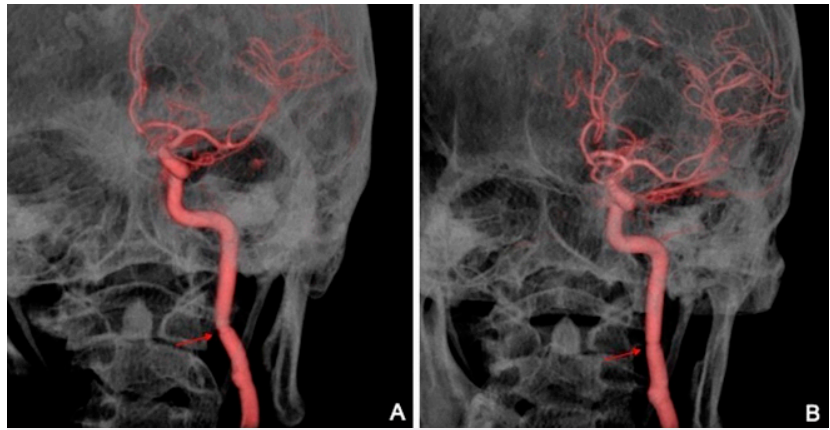

FIG. 3. DSA showing that the ICA (red arrows) is bent when the patient's neck is flexed in the left-downward direction (A) compared with when it is in the neutral position (B).

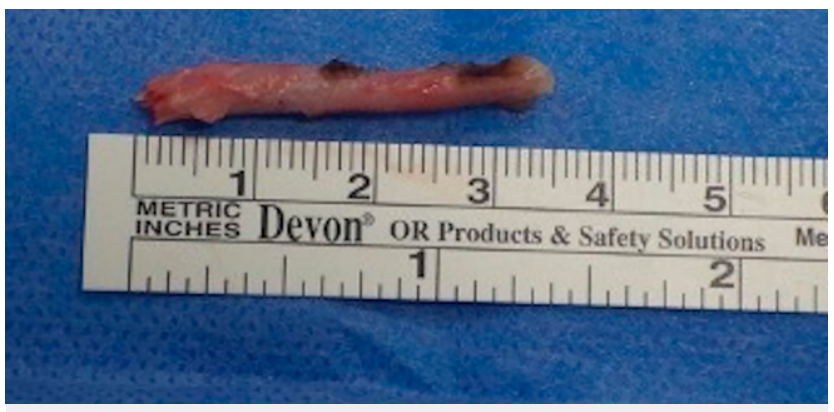

FIG. 4. Removal of the styloid process, which measured $3.5 \mathrm{~cm}$.

to the spatial positioning relationship between the styloid process and the carotid artery. Li et al. reported a case of transient ischemic attack in which transcranial Doppler imaging combined with color Doppler flow imaging showed a marked decrease in blood flow in the middle cerebral artery, ${ }^{12}$ thereby revealing the usefulness of simultaneous assessment of intracranial and extracranial hemodynamics.
In the present case, the relationship between elongated styloid process and stroke was not clear because of the absence of morphological changes in the ICA. Dynamic ultrasonography with cervical rotation showed that the PSV and PI increased only when the patient rotated his head leftward. The elevation of PSV usually means stenosis of blood vessels, and PI increases also imply peripheral vascular resistance increases. These hemodynamic changes made us think that the indirect compression of the ICA by the elongated styloid process caused strokes.

In patients with a cerebral infarction who have an elongated styloid process, the possibility of developing stylocarotid syndrome should be considered even if continuous compression of the blood vessels is absent. Ayyildiz et al. emphasized the importance of not only the length of the styloid process but also its medial angulation. ${ }^{13}$ They indicated that the deviations of the styloid process and its length as well as the surrounding structures may cause Eagle syndrome. In previous reports, changes in blood flow were observed only in patients with obvious morphological changes in the ICA. Our report is the first to document the occurrence of stylocarotid syndrome due to indirect compression by the styloid process, and morphological change in the ICA was first evident when the patient rotated his head leftward.

Styloidectomy is the gold standard treatment for Eagle syndrome. Although a transcervical approach has been used, ${ }^{14-18}$ a transoral approach is usually chosen. Because it is difficult to expose the deeper part of the styloid process, the transcervical approach is the more suitable option for stylocarotid syndrome. In some cases, carotid artery stenting was performed. ${ }^{10,19}$ Miyata et al., ${ }^{10}$ for example, used this procedure along with styloidectomy for treatment of stent compression by the styloid process due to cervical rotation.

\section{Lessons}

In conclusion, we encountered a case of repeated cerebral infarction associated with Eagle syndrome. Our case shows that indirect compression of the ICA by an elongated styloid process can cause stylocarotid syndrome. Dynamic ultrasonography with cervical rotation centered on ipsilateral head movement may be useful for diagnosis of hidden stylocarotid syndrome.
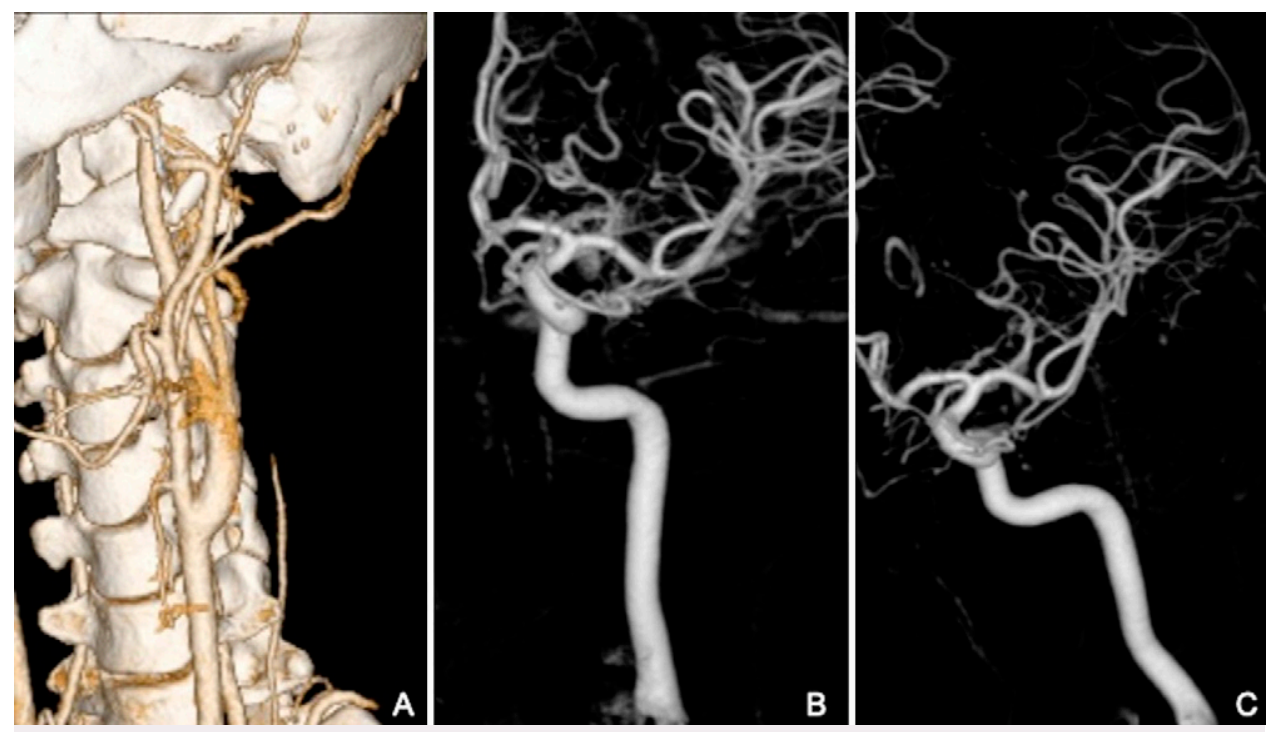

FIG. 5. 3D-CTA confirms the removal of the left styloid process (A). After the surgery, DSA with the head in the neutral position (B) and left-downward position (C) shows no morphological changes. 


\section{Acknowledgments}

We would like to thank Editage for English language editing.

\section{References}

1. Eagle WW. Elongated styloid processes: report of two cases. Arch Otolaryngol. 1937;25(5):584-587.

2. Monsour PA, Young WG. Variability of the styloid process and stylohyoid ligament in panoramic radiographs. Oral Surg Oral Med Oral Pathol. 1986;61(5):522-526.

3. Langlais RP, Miles DA, Van Dis ML. Elongated and mineralized stylohyoid ligament complex: a proposed classification and report of a case of Eagle's syndrome. Oral Surg Oral Med Oral Pathol. 1986;61(5):527-532.

4. Kaufman SM, Elzay RP, Irish EF. Styloid process variation. Radiologic and clinical study. Arch Otolaryngol. 1970;91(5):460-463.

5. Koshy J, Narayan M, Narayanan S, et al. Elongated styloid process: a study. J Pharm Bioallied Sci. 2015;7(5):S131-S133.

6. Eagle WW. Elongated styloid process: further observations and a new syndrome. Arch Otolaryngol. 1948;47(5):630-640.

7. Härmä R. Stylalgia: clinical experiences of 52 cases. Acta Otolaryngol. 1966;63(suppl 224):149.

8. Bruno G, De Stefani A, Balasso P, et al. Elongated styloid process: an epidemiological study on digital panoramic radiographs. J Clin Exp Dent. 2017;9(12):e1446-e1452.

9. Chuang WC, Short JH, McKinney AM, et al. Reversible left hemispheric ischemia secondary to carotid compression in Eagle syndrome: surgical and CT angiographic correlation. AJNR Am J Neuroradiol. 2007;28(1):143-145.

10. Miyata $\mathrm{H}$, Nakahara I, Ohta $\mathrm{T}$, et al. A case of internal carotid artery dissection caused by an elongated styloid process: successful treatment with carotid artery stenting and partial resection of the styloid process. Surg Cereb Stroke. 2016;44(2):145-150.

11. Smoot TW, Taha A, Tarlov N, Riebe B. Eagle syndrome: a case report of stylocarotid syndrome with internal carotid artery dissection. Interv Neuroradiol. 2017;23(4):433-436.

12. Li Z, Hua Y, Yang J, Li J. Ultrasound evaluation of transient ischemic attack caused by styloid process elongation: a case report. Front Neurol. 2019;10:26.

13. Ayyildiz VA, Senel FA, Dursun A, Ozturk K. Morphometric examination of the styloid process by 3D-CT in patients with Eagle syndrome. Eur Arch Otorhinolaryngol. 2019;276(12):3453-3459.
14. Pigache P, Fontaine C, Ferri J, Raoul G. Transcervical styloidectomy in Eagle's syndrome. Eur Ann Otorhinolaryngol Head Neck Dis. 2018;135(6):433-436.

15. Badhey A, Jategaonkar A, Anglin Kovacs AJ, et al. Eagle syndrome: a comprehensive review. Clin Neurol Neurosurg. 2017;159:34-38.

16. Gallaway E, Bayoumi S, Hammond D, Halsnad M. Case report: an atypical presentation of Eagle syndrome. J Surg Case Rep. 2017;2017(8):rjx152.

17. Liu $Y$, Yang $H$, Cui X. A case of a very elongated styloid process. Clin Med Insights Ear Nose Throat. 2017;10:1179550617728899.

18. Ceylan A, Köybaşioğlu A, Çelenk $F$, et al. Surgical treatment of elongated styloid process: experience of 61 cases. Skull Base. 2008;18(5):289-295.

19. Todo T, Alexander M, Stokol C, et al. Eagle syndrome revisited: cerebrovascular complications. Ann Vasc Surg. 2012;26(5): 729.e1-729.e5.

\section{Disclosures}

The authors report no conflict of interest concerning the materials or methods used in this study or the findings specified in this paper.

\section{Author Contributions}

Conception and design: Anami, Miyao. Acquisition of data: Anami, Tanaka, Miyao. Analysis and interpretation of data: Miyao, Kubota. Drafting the article: Miyao. Critically revising the article: Miyao. Reviewed submitted version of manuscript: Miyao, Nakamoto. Administrative/technical/material support: Kurihara, Kubota. Study supervision: Kubota, Kawamata.

\section{Supplemental Information}

Previous Presentations

Portions of this work were presented at Stroke2020, Annual Meeting of the Japanese Society on Surgery for Cerebral Stroke, Yokohama, Japan, March 26, 2020.

\section{Correspondence}

Hidenori Anami: TMG Asaka Medical Center, Saitama, Japan. hidenori272@gmail.com. 